\title{
Birleştirilmiş ve Bağımsız Sınıflarda Çalışan Sınıf Öğretmenlerinin Mesleki Doyum ve Tükenmişlik Düzeylerinin Karşılaştırılması"
}

\section{A Comparison of Combination Classroom Teachers' and Single-Grade Teachers' Job Satisfaction and Burnout Levels}

\author{
Nuri Barış İNCE ${ }^{* *}$, Ali E. ŞAHIIN ${ }^{* * *}$
}

ÖZ: Araştırmanın amacı, birleştirilmiş ve bağımsız sınıfta görev yapan sınıf öğretmenlerinin mesleki doyum ve tükenmişlik düzeylerinin belirlenmesi ve karşılaştırılmasıdır. Çalışmanın verileri 2013-2014 eğitim-öğretim yılı birinci döneminde Ankara ilinin merkez ve taşra ilçelerinde bağımsız sınıfta görev yapan 465 sınıf öğretmeni ve birleştirilmiş sınıfta çalışan 75 sınıf öğretmeninden elde edilmiştir. Sınıf öğretmenlerinin mesleki doyum düzeyleri Minnesota İş Doyum Ölçeği-Kısa Formu (MIDÖ-KF), tükenmişlik düzeyleri ise Maslach Tükenmişlik EnvanteriEğitimci Formu (MTE-EF) kullanılarak belirlenmiştir. Araştırmadan elde edilen bulgular birleştirilmiş ve bağımsız sınıfta çalışan sınıf öğretmenlerinin genel iş doyumlarının orta düzeyde olduğunu göstermektedir. Birleştirilmiş ve bağımsız sınıfta çalışan öğretmenler duygusal tükenme boyutunda orta, duyarsızlaşma boyutunda düşük düzeyde tükenmişlik yaşamaktadır. Kişisel başarı boyutunda ise bağımsız sınıfta görev yapan öğretmenler düşük, birleştirilmiş sınıfta çalışan öğretmenler orta düzeyde tükenmiştir. Sınıf öğretmenlerinin mesleki doyum ve tükenmişlik düzeyleri birleştirilmiş ve bağımsız sınıfta çalışma durumuna göre karşılaştırıldığında bağımsız sınıfta çalışan öğretmenler lehine istatistiksel olarak anlamlı farklılıklar elde edilmiştir. Bağımsız sınıfta çalışan öğretmenler içsel doyum ve genel doyum boyutunda daha fazla iş doyumu yaşamaktadır. Ayrıca kişisel başarı boyutunda birleştirilmiş sınıfta çalışan sınıf öğretmenlerine göre anlamlı biçimde daha az tükenmişlik yaşadıkları tespit edilmiştir.

Anahtar sözcükler: Birleştirilmiş sınıflarda öğretim, sınıf öğretmeni, iş doyumu, tükenmişlik.

\begin{abstract}
The purpose of this study was to determine and compare job satisfaction and burnout levels of primary school teachers working in combination and single-grade classrooms. The data were collected from 465 primary school teachers who work in single-grade classrooms and 75 primary school teachers who work in combination classrooms in the central towns and rural areas of Ankara in the first semester of 2013-2014 academic year. The job satisfaction levels of the primary school teachers were measured through Minnesota Job Satisfaction QuestionnaireShort Form (MSQ-SF), and burnout levels were measured through Maslach Burnout Inventory-Educators Survey (MBI-ES). The results indicated that general job satisfaction level of the primary school teachers working in combination and single-grade classrooms was at medium level. They experienced emotional exhaustion at a medium level and depersonalization at a low level. The teachers of single-grade classrooms had a low level of personal accomplishment, while the teachers of combination classrooms had a medium level of burnout. Statistically significant differences were found as a result of the comparison between the teachers in combination and single-grade classrooms in terms of job satisfaction and burnout levels.
\end{abstract}

Keywords: Teaching in combination classrooms, primary school teacher, job satisfaction, burnout.

\footnotetext{
* Bu çalışma, ilk yazarın ikinci yazar yönetiminde hazırladığı ve 09.07.2014 tarihinde tamamlanan "Birleştirilmiş ve Bağımsız Sınıf Öğretmenlerinin Mesleki Doyum ve Tükenmişlik Düzeylerinin Karşılaştırılması” isimli yüksek lisans tezinin bir kismidır.

** Arş. Gör., Hacettepe Üniversitesi, Eğitim Fakültesi, Ankara-Türkiye, e-posta: nbaris.ince@ hacettepe.edu.tr

**** Doç. Dr., Hacettepe Üniversitesi, Eğitim Fakültesi, Ankara-Türkiye, e-posta: alisahin@ @acettepe.edu.tr
} 


\section{GíRiş̧}

Eğitim ve öğretim hakkı Türkiye Cumhuriyeti Anayasası tarafından güvence altına alınan, kapsamı ilgili yasalarca tespit edilen ve düzenlenen sosyal bir hak ve ödevdir. Bu en temel hak ve ödev; hiçbir kişiye, aileye, zümreye veya sınıfa imtiyaz tanınmadan, dil, ırk, cinsiyet ve din ayrımı gözetmeksizin herkese açık bir şekilde örgün ve yaygın eğitim kurumlarında gerçekleştirilir. Vatandaşların bu temel haktan en geniş şekilde yararlanmaları bireysel fayda sağlamanın yanında toplumsal sürekliliğe de hizmet eder.

Türk Eğitim Sisteminde örgün eğitimin kapsamı okul öncesi eğitim, temel eğitim, ortaöğretim ve yükseköğretim olarak belirlenmiştir. Örgün eğitim içerisinde ortaöğretimin temel eğitime, yükseköğretimin de ortaöğretime dayalı olması ve zorunlu eğitimin kapsamı temel eğitim ve ortaöğretim kurumlarının yaygınlaştırılmasını ve her bir öğrenci için erişilebilir hale getirilmesini gerekli kılmaktadır. Birleşmiş Milletler Ekonomik, Sosyal ve Kültürel Haklar Komitesi'nin (1999) eğitim hakkının uygulanmasına ilişkin 13 numaralı gözlem raporu bütün eğitim kurumlarının hiçbir ayrım gözetilmeksizin fiziksel ve ekonomik olarak herkes için erişilebilir olması gerektiğini ifade etmektedir. Ancak ülke coğrafyası, nüfus dağılımı, öğretmen ve derslik sayıları zaman zaman zorunlu tutulan eğitim hakkına erişimi sınırlandırabilmektedir.

Örgün eğitim sistemi içerisinde "ilkokul" olarak adlandırılan temel eğitim kurumları zorunlu eğitim sürecinin başlangıcı olması açısından son derece önemlidir. "En iyi okul öğrencinin en yakınındaki okuldur." yaklaşımıyla öğrencilerin adrese dayalı kayıt sistemiyle yaşadıkları çevredeki okula devam etmeleri amaçlanır. Bir yerleşim bölgesinde bağımsız sınıf oluşturacak sayıda öğrenci olmaması, yeterli sayıda derslik ya da öğretmen bulunamaması durumlarında taşımalı eğitim sistemleriyle, yatılı bölge okulu ve pansiyonlu eğitim uygulamalarıyla, birleştirilmiş sınıflarda öğretim ile eğitim hakkına erişimin sağlanmasına çalışılmaktadır. Milli Eğitim Bakanlığının 2012-2013 eğitim-öğretim yılına ait verilerine göre resmi ilkokullarda öğrenim gören 5.426.529 öğrenciden yaklaşık olarak \%5'i birleştirilmiş sınıflarda öğrenim görmektedir. Birleştirilmiş sınıf uygulamalarına ilişkin öğrenci sayıları böyleyken Milli Eğitim Bakanlığına Bağlı Okul ve Kurumların Yönetici ve Öğretmenlerinin Norm Kadrolarına İlişkin Yönetmeliğin 10. Maddesi ise ilkokullarda öğrenci sayısı 10'dan az olmamak koşuluyla her sınıf ve şube için bir sınıf öğretmeni norm kadrosu verileceğini belirtmektedir. Bu koşullar altında 1. sınıf ile 4. sınıf aralığındaki herhangi bir sınıf düzeyinde öğrenci sayısı 10'un altında kaldığı durumlarda sınıfların birleştirilmesi seçeneği gündeme gelmektedir.

İlkokul kademesindeki birden fazla sınıf düzeyinin aynı derslikte birleştirilerek tek öğretmen ile eğitim-öğretim etkinliklerinin sürdürülmesi yaklaşımı birleştirilmiş sınıf uygulamalarının genel çerçevesini meydana getirmektedir. Brunswic ve Valérien (2004, s. 19) "geleneksel bağımsız sınıfların aksine birden fazla sınıfın eş zamanlı olarak aynı derslikte bir öğretmen tarafindan öğretim faaliyetlerini sürdürmesini birleştirilmiş sınıflarda öğretim” olarak ifade etmektedir. Birleştirilmiş sınıflarda "öğretmenler bir eğitim döneminde iki ya da daha fazla sınıfın öğretim programından sorumludur" (Little, 2001, s. 482). Birleştirilmiş sınıf uygulamalarında Hayat Bilgisi, Sosyal Bilgiler ile Fen ve Teknoloji derslerinin ortak olarak işlenmesi, derslerin öğretmenli ve kendi kendine çalışma saatleri olarak sürdürülmesi, haftalık ders dağıtım çizelgelerinin oluşturulma şekilleri birleştirilmiş sınıflara özgü düzenlemeler olarak gözükmektedir (Şahin, 2003).

Birleştirilmiş sınıflara özgü eğitim düzenlemeleri ve göz ardı edilemeyecek sayıda öğrencinin varlığı birleştirilmiş sınıfların bazı olumlu yanlarını ve sınıllılıklarını gündeme getirmektedir. Köksal (2005, s. 176) birleştirilmiş sınıfların "grup çalışmasına, bağımsız çalışmaya, arkadaştan öğrenmeye, çevre ile bütünleşmeye bağımsız sınıflardan daha çok imkân verdiğini” düşünmektedir. Öğretmenlerin lisans eğitimlerinin yeterli olmaması, birleştirilmiş sınıflarda öğretim materyallerinin yetersiz olması, ailelerin ekonomik koşullarının iyi olmaması 
gibi nedenler birleştirilmiş sınıflarda karşılaşılan güçlükler arasındadır (Erden, 1996). Ayrıca bağımsız sınıflarda uygulanan öğretim programlarının birleştirilmiş sınıflar için de geçerli olması, deneyimsiz öğretmenlere birleştirilmiş sınıflarda görev verilmesi sınıf öğretmenlerini mesleki açıdan zorlayan deneyimler ile karşı karşıya bırakmaktadır.

Sınıf öğretmenleri birleştirilmiş sınıf uygulamalarının yanı sıra bağımsız sınıflarda da bazı sorunlarla karşılaşmaktadır. Kalabalık sınıflar, disiplin sorunları, şiddet, düşük maaşlar, ilgisiz ebeveynler, olumsuz yönetici tutumları gibi sorunlarla karşı karşıya kalmaları öğretmenlerin stres yaşamalarına neden olmaktadır (Russell, Altmaier ve Van Velzen, 1987). Ertürk ve Keçecioğlu (2012) birleştirilmiş sınıfta görev yapan sınıf öğretmenlerinin bağımsız sınıfta çalışan öğretmenlere göre materyal eksiklikleri, ulaşım ve 1sınma sorunları, sınıfların sosyoekonomik düzeyi düşük ailelerin çocuklarından oluşmasının getirebileceği stres yapıcı durumlarla daha çok karşılaşma potansiyelleri bulunduğunu savunmaktadır. Birleştirilmiş sınıflı okullarda ise birden fazla sınıf düzeyinin bulunması nedeniyle öğretimin planlanması, sürdürülmesi ve değerlendirilmesi boyutlarında artan iş yükü, okulların altyapısının ve eğitim materyallerinin yetersizliği, köy halkının ve öğrenci velilerinin ilgisizliği (Kaya ve Taşdemirci, 2005; Gözler, 2009; Sağ, Savaş ve Sezer, 2009; Gömleksiz, Cüro ve Kılınç, 2011; Kazu ve Aslan, 2012; Kudal ve Altun, 2012) sonucu sınıf öğretmenleri bu okullarda çalışmak istememekte, birleştirilmiş sınıflarda öğretime son verilmesi gerektiğini düşünmekte ya da bağımsız sınıfta öğretmenlik yapabileceği bir okula geçmeyi düşünmektedir. Öğretmenlerin karşılaştıkları bu sorunlar mesleki memnuniyetleri açısından ruh sağlıklarını da olumsuz yönde etkilemektedir (Erdem ve Yaprak, 2011).

Öğretmenler çalışma yaşamları boyunca bulundukları örgütte birçok deneyim elde etmektedir. Çalışanların beklentileri ile içinde yer aldıkları örgütün onlara sunduklarının örtüşmesi sonucu mesleki (iş) doyum gerçekleşmektedir. Luthans (1992, s. 114), iş doyumunu "iş görenlerin önemli olarak gördükleri şeyleri işlerinden ne kadar elde ettiklerine ilişkin algılarının bir sonucu" olarak tanımlamaktadır. Bireylerin işlerine gösterdikleri tepkilere dayalı olarak yapılan genel iş doyumu tanımları giderek detaylandırılmış ve işin çeşitli boyutlarına vurgu yapan iş doyumu tanımları geliştirilmiştir. Bu yaklaşıma göre çalışma ortamında işin bizzat kendisi, ücret, çalışma koşulları, yükselme ve gelişme olanakları, birlikte çalışılan kimseler ve örgütsel ortam gibi iş doyumu boyutlarına ilişkin değerler bulunmaktadır ve çalışanlar bu değerlerin elde edilmesine yönelik bir muhasebe içine girmektedir (Balc1, 1983).

Çalışanların mesleki doyumunu etkileyen birçok faktör bulunmaktadır. "İş görenin genetik eğilimi, aile faktörü, almış olduğu eğitim, değer yargıları, iş hayatı tecrübesi, içinde yaşadığı sosyal yapı ve çevresi" iş doyumu üzerinde önemli rol oynayan bireye ilişkin faktörlerdir (Akınc1, 2002, s. 4). Tengilimoğlu (2005, s. 28) "işin niteliği, yönetim tarzı ve denetim biçimi, güvenlik, iletişim, ücret, gelişme ve yükselme imkânları, birlikte çalışılan kişiler ve çalışma şartlarını" örgütsel faktörler olarak nitelendirmektedir. Herzberg ise "Çift Faktör Teorisi" olarak bilinen motivasyon-hijyen teorisinde işin kendisi, sorumluluk, ilerleme, gelişme, başarma ve tanınma gibi faktörleri motive edici faktörler; yönetim, denetim, çalışma koşulları, ücret, çalışma arkadaşları ile ilişkiler, statü ve iş güvencesi gibi faktörleri ise hijyen faktörleri olarak belirtmektedir (Herzberg, 1987). Motive edici faktörler kişisel başarı hissi verdiği için çalışanların iş doyumu sağlamalarına yol açarken hijyen faktörleri ise bireylerin iş doyumsuzluğu yaşamalarını engellemektedir (Koçel, 2007). Mesleki doyum faktörlerinin etkileşimde bulunduğu süreçte bireyin işine iliş̧kin sahip olduğu olumlu ya da olumsuz tutumlar mesleki doyum düzeyine etki etmektedir. İşinden yeterince doyum sağlayamayan ve yaşadığı doyumsuzlukla başa çıkamayan bireyler tükenmişlik duygusuyla karşı karşıya kalabilmektedir.

Son yıllarda popüler bir kavram olarak birçok araştırmaya konu olan tükenmişlik kavramı Freudenberger (1974, s. 159) tarafindan "enerji, güç ve kaynaklar üzerindeki aşırı taleplerden dolayı kişinin başarısız olması, yıpranması ve tükenmiş hale gelmesi” şeklinde tanımlanmıştır. 
Maslach'a (2003) göre tükenmişlik, iş yerindeki stres yapıcı unsurlara karşı bir tepki olarak uzun sürede ortaya çıkan psikolojik bir sendrom, çalışan ile işi arasındaki uyumsuzluğun sonucu oluşan kronik bir gerginlik durumudur. Maslach, tükenmişlik kavramını duygusal tükenme, duyarsızlaşma ve kişisel başarı olmak üzere üç boyutu olan bir süreç olarak değerlendirmektedir. Maslach modeline göre insanların psikolojik taleplerine daha fazla cevap veremeyecek konuma gelen çalışanlar ilk olarak duygusal tükenme yaşamaktadır (Maslach ve Jackson, 1981). İş ortamındaki aşırı taleplerle başa çıkamayan çalışanlar hizmet verdikleri insanlara karşı mesafe alarak duyarsızlaşırken; içinde bulundukları topluma ve çalıştıkları kuruma yapmayı bekledikleri katkı ile mevcut davranışları arasında uyumsuzluk olduğunu fark etmekte ve kişisel başarılarının yetersiz olduğunu düşünmektedir (Cordes ve Dougherty, 1993).

Cinsiyet, yaş, medeni durum, eğitim düzeyi, kişilik gibi bireysel değişkenler iş doyumu kavramında olduğu gibi tükenmişlik düzeyini de etkilemektedir. Bireysel faktörlerin yanı sıra iş yükü, kontrol, ödüller, aidiyet, adalet ve değerler ise meslekteki tükenmişliği etkileyen örgütsel faktörler olarak nitelendirilmektedir (Leiter ve Maslach, 2003). Cordes ve Dougherty (1993) ise işte rol belirsizliklerini, görev tanımlarının net olmamasını, iş yükünü, kişi-rol çatışmasını, işi tamamlamak için gereken becerilerin ve sürenin yetersizliğini tükenmişliğe neden olan örgütsel etkenler olarak siralamaktadır.

Mesleki doyum ve tükenmişliğin ayrı ayrı ele alındığı zengin bir literatür bulunmakla birlikte iki kavramın bir arada kullanıldığı ulusal ve uluslararası araştırmalar da bulunmaktadır. $\mathrm{Bu}$ araştırmalardan birisinde Friesen \& Sarros (1989) "Eğitimcilerdeki Tükenmişliğin Kaynakları" isimli çalışmalarında okul yöneticileri ve öğretmenlerdeki tükenmişliği yordayan iş doyumu değişkenlerini tespit etmeyi amaçlamışlardır. Araştırmanın öğretmenler ile ilgili bulguları genel iş stresinin öğretmenlerin duygusal tükenmişliklerini; işin zorluğunun duyarsızlaşma düzeylerini; statü ve tanınmadan elde edilen doyum ise kişisel başarı boyutunu yordamada en büyük katkı veren değişkenler olduğunu göstermiştir. Türkiye'deki özel okul müdürleri ve öğretmenlerinin iş doyumu ve tükenmişliklerini tespit etmeyi amaçlayan başka bir araştırmada ise okul müdürlerinin kişisel başarı hisleri öğretmenlere göre anlamlı düzeyde daha düşük çıkarken; duygusal tükenme, duyarsızlaşma ve iş doyumu düzeylerinde okul müdürleri ve öğretmenler arasında anlamlı bir farklılık çıkmamıştır (Sarı, 2004). Sevilla bölgesinde çalışan öğretmenlerin tükenmişliğini yordayan kişilikle ilişkili olan ve örgütsel bağlamdaki değişkenleri belirlemek amaciyla Cano-Garcia, Padilla-Munoz \& Carrasco-Ortiz (2005) bir araştırma gerçekleştirmiştir. Araştırmacıların analizlerine göre duygusal tükenmişlik düzeyine ait toplam varyansın \%72'sini açıklayan altı tane değişkenin; yöneticilerle ilişkilerin yetersizliği, yüksek düzeyde duygusal dengesizlik durumunda bulunmak, terfi imkânlarının eksik olması, mesleki saygınlığın az olduğunun farkında olmak, uzun bir süre işteki aynı pozisyonda kalmak ve öğrenci sayısı olduğu tespit edilmiştir. Kişisel başarı boyutunda açıklanan toplam varyansın \%53'ünü ise yüksek düzeyde yakın kişiler arası ilişkiler, özel bir kurumda ders vermek ve öğrencilerle olan ilişkilere bir değer atfetmek oluşturmaktadır. Ayrıca yüksek düzeyde duyarsızlaşmanın en iyi yordayıcı değişkeni olarak düşük düzeyde puanlanan yakın kişiler arası ilişkilerin düzeyi bulunmuştur.

Sınıf öğretmenlerinin öğretim faaliyetlerini yerine getirdikleri hedef kitle temel eğitim dönemindeki öğrencilerden oluşmaktadır. $\mathrm{Bu}$ dönemde eğitimini nitelikli bir şekilde alan öğrencilerin örgün eğitim basamaklarını tamamlayarak toplumun çeşitli kademelerinde yaşamlarına devam etmeleri beklenmektedir. Önemli bir topluluğa hizmet eden sınıf öğretmenlerinin mesleki doyumsuzluk ve tükenmişlik yaşayarak kendisine, öğrencilerine, öğretmen arkadaşlarına ve ailesine zarar verecek söylem ve eylemlerde bulunması istenilen bir durum değildir. Öğretmenlerden asıl beklenen ise öğrencilerin değişen yaşam koşullarına uyum sağlamasına yardımcı olurken, öncelikle birey olarak kendisini geliştirmesi, problemlerini çözebilen bir kişi olmasıdır (Bozkurt, 2004). Ancak bazı araştırmalar tükenmişlik düzeyi yüksek öğretmenlerin olumsuz öğrenci davranışları karşısında bağırmayı, kızmayı veya küçük düşürücü 
sözel tepkiler vermeyi tercih ettiğini göstermektedir (Karakelle ve Canpolat, 2008). Başka bir açıdan bakıldığında iş doyum düzeyi yüksek olan öğretmenler engellenme karşısında uyum ve sabır gösteren, çözüm arayan ve saldırganlıktan kaçınan davranışlar gösterirken; iş doyum düzeyi düşük olan öğretmenler ise bir engel ile karşı karşıya kaldıklarında saldırgan tavırla reddetmekte ya da koşulları öne sürerek kaçınmaya çalışmaktadır (Minibaş, 1990). Dolayısıyla sınıf öğretmenlerinin birleştirilmiş ve bağımsız sınıf uygulamalarında işlerinden duydukları doyum ve yaşadıkları tükenmişlik düzeylerini karşılaştırmalı olarak belirlemenin öğretmenlerin bağımsız ya da birleştirilmiş sınıfta görev almaya ilişkin düşünürken dikkate alacakları bulgular sağlaması bakımından önemli görülmektedir. Ayrıca mesleki sorunlarının ve yoksunluklarının doyum ve tükenmişliğin boyutlarına olan yansımalarını öğretmenlerin ne düzeyde algıladıklarına ilişkin ortaya çıkan sonuçların öğretmenlerin mesleki memnuniyetlerini arttırmada politika yapıcıların öncelikle önemsemesi gereken başlıkları göstermesi bakımından yararlı olacağı düşünülmektedir. Bu bakış açısı ile araştırmanın problem cümlesi ve alt problemleri aşağıdaki gibi düzenlenmiştir.

\subsection{Problem Cümlesi}

Sınıf öğretmenlerinin mesleki doyum ve tükenmişlik düzeyleri birleştirilmiş ve bağımsız sınıfta çalışma durumuna göre anlamlı farkl11ık göstermekte midir?

\subsubsection{Alt Problemler}

1.Bağımsız sınıfta görev yapan sınıf öğretmenlerinin mesleki doyum ve tükenmişlikleri hangi düzeydedir?

2.Birleştirilmiş sınıfta görev yapan sınıf öğretmenlerinin mesleki doyum ve tükenmişlikleri hangi düzeydedir?

\section{YÖNTEM}

Nicel bir yaklaşımın benimsendiği bu araştırma sınıf öğretmenlerinin mevcut mesleki doyum ve tükenmişlik düzeylerini belirlemesi yönünden betimsel niteliktedir. Ayrıca bu çalışma sınıf öğretmenlerinin mesleki doyum ve tükenmişlik düzeylerinin birleştirilmiş ve bağımsız sınıfta çalışma durumuna göre farklılık gösterip göstermediğini araştırdığı için ilişkisel nitelikte bir çalışmadır.

\subsection{Evren ve Örneklem}

Ankara ilindeki resmi ilkokullarda çalışan sınıf öğretmenleri araştırmanın evrenini meydana getirmektedir. Ankara İl Milli Eğitim Müdürlüğü istatistiklerine göre 2012-2013 eğitim-öğretim yılında Ankara'da 15544 sınıf öğretmeni görev yapmaktadır. Çevresel faktörlerin öğretmenlerin iş doyumu ve tükenmişlik düzeyleri üzerindeki etkisini azaltabilmek için bağımsız sınıfta öğretim faaliyetlerini sürdüren sınıf öğretmenlerinden oluşan örneklem birleştirilmiş sınıflı okulların bulunduğu ilçelerden belirlenmiştir. Ankara'da bu ölçütü karşılayan 5 merkez ve 9 taşra olmak üzere 14 ilçe olduğu ve bu ilçelerde 8057 sinıf öğretmeninin çalıştığı tespit edilmiştir. Örnekleme yöntemi olarak tabakalı örnekleme yöntemine gidilerek her ilçe birer tabaka olarak belirlenmiştir. Bu ilçelerdeki resmi ilkokullar örneklem birimi olarak kabul edilerek küme örneklemeye yer verilmiş ve her bir ilçedeki okullar basit seçkisiz yöntemle seçilerek örnekleme alınmıştır.

Bağımsız sınıflarda çalışan öğretmenlerin örneklem büyüklüğünü belirlemek için $\% 5$ hata payı (Çıngı, 1990) esas alınmış ve 465 öğretmene veri toplama aracı uygulanmıştır. Araştırmada yer alan her bir ilçedeki toplam sınıf öğretmeninin evrendeki ağırlığ alması gerektiğine dikkat edilmiştir. Birleştirilmiş sınıfta çalışan öğretmenlerden ise örneklem alma yoluna gidilmeyerek araştırma evrenindeki tüm öğretmenlere ulaşılmaya çalışılmıştır. Bağımsız sınıfta çalışan öğretmenlerden alınan örneklemin özellikleri incelendiğinde çoğunlukla 
40 yaşın altında (\%59.3), medeni durum yönünden evli (\%88.4), kadın öğretmenlerden (\%75.7) oluştuğu anlaşılmaktadır. Sınıf öğretmenliği programından mezun olan öğretmenler (\%61.3), kadrolu olarak çalışan öğretmenler (\%95.3) ve 15 y1la kadar hizmet y1lı (\%53.8) bulunan öğretmenler ağırlıktadır. Bağımsız sınıfta çalışan öğretmenler çoğunlukla 1. ya da 2. sınıfta görev yapmakta (\%63.2) ve sinıflarında 26 ve üzerinde öğrenci (\%50.6) bulunmaktadır. Birleştirilmiş sınıfta çalışan sınıf öğretmenlerinden elde edilen kişisel verilere göre örneklem genellikle 30 yaş ve altında öğretmenlerden (\%66.7), evli öğretmenlerden (\%85.3) ve kadın öğretmenlerden (\%66.7) oluşmaktadır. Örneklemin çoğunluğu mezuniyet yönünden sinıf öğretmenliği programından mezun (\%81.3), 5 yıla kadar hizmet y1lı bulunan (\%60), kadrolu olarak çalışan (\%88) öğretmenlerden meydana gelmektedir. Birleştirilmiş sınıflarda görev yapan öğretmenlerin önemli bir bölümü lisans döneminde birleştirilmiş sınıflarda öğretim dersi almış (\%73.3) ancak uygulama yapmamıştır (\%78.7). Ayrıca öğretmenler genellikle birleştirilmiş sınıflarla ilgili hizmet içi eğitim çalışmalarına katılmamıştır (\%90.7). Sınıf öğretmenleri genellikle 15 ve altında öğrenci mevcudunun (\%60) bulunduğu okullarda çalışmaktadır.

Örneklemde yer alan bağımsız ve birleştirilmiş sınıflarda çalışan sınıf öğretmenlerinin ilçelere göre dağılımına Tablo 1'de yer verilmektedir.

Tablo 1: Sınıf öğretmenlerinin ilçelere göre dağılımı

\begin{tabular}{lcc}
\hline İlçeler & Bağımsı Sınıf & Birleştirilmiş Sınıf \\
\hline Çankaya & 90 & 2 \\
\hline Sincan & 75 & 1 \\
\hline Altındağ & 69 & - \\
\hline Etimesgut & 59 & 1 \\
\hline Gölbaşı & 31 & 8 \\
\hline Beypazarı & 11 & - \\
\hline Ayaş & 11 & 3 \\
\hline Polatlı & 33 & 12 \\
\hline Akyurt & 18 & 3 \\
\hline Çubuk & 19 & 7 \\
\hline Haymana & 13 & 18 \\
\hline Kalecik & 10 & 5 \\
\hline Bala & 6 & 12 \\
\hline Şereflikoçhisar & 20 & 75 \\
\hline Toplam & 465 & 3 \\
\hline
\end{tabular}

Tablo 1'e göre Ankara'nın merkez ilçeleri olan Çankaya, Sincan, Altındağ, Etimesgut ve Gölbaşı ilçelerinde çalışan 324 sınıf öğretmeni; Beypazarı, Ayaş, Polatlı, Akyurt, Çubuk, Haymana, Kalecik, Bala ve Şereflikoçhisar ilçelerinden ise 141 sınıf öğretmeni araştırmaya katılmıştır. 14 ilçede çalışan 86 öğretmenden $75^{\prime}$ ine ulaşılarak \%87 oranında bir erişim sağlanmıştır. Araştırmaya katılan birleştirilmiş sınıflarda görev yapan öğretmenlerin tamamı merkez ya da taşra ilçelere bağlı köylerde görev yapan öğretmenlerdir.

\subsection{Veri Toplama Aracı}

Birleştirilmiş ve bağımsız sınıfta çalışan sınıf öğretmenlerinin mesleki doyum ve tükenmişlik düzeylerini belirlemek için uygulanan veri toplama aracı üç bölümden oluşmaktadır. 
Aracın ilk bölümü araştırmacılar tarafından geliştirilen kişisel bilgi formundan meydana gelmektedir. Veri toplama aracının ikinci bölümünde sınıf öğretmenlerinin tükenmişlik düzeylerini belirlemek için Maslach Tükenmişlik Envanteri-Eğitimci Formu'na (MTE-EF) yer verilmektedir (Ek-1). Maslach, Jackson ve Schwab, 1981 y1lında Maslach ve Jackson tarafindan geliştirilen Maslach Tükenmişlik Envanterini (MTE) bazı değişikliklerle eğitimcilere uyarlayarak MTE-EF'yi elde etmiştir. Veri toplama aracının üçüncü bölümünde ise öğretmenlerin iş doyum düzeylerini belirlemek amaciyla Weiss, Dawis, England ve Lofquist (1967) tarafından geliştirilen Minnesota İş Doyum Ölçeği-Kısa Formu (MİDÖ-KF) kullanılmıştır (Ek-2).

Her iki ölçeğin İngilizce özgün formundan Türkçeye uyarlama çalışması yapılmıştır. Ölçeklerde yer alan maddeler Türkçeye çevrilerek bir taslak hazırlanmış ve uzman görüşüne başvurulmuştur. Çeviri taslak formuna ölçekteki orijinal maddeler ile Türkçe karşılıkları yazılarak ifadelerin uygun olup olmadığı sorulmuştur. Çeviri ifadelerinin uygun olmadığını düşünen uzmanların düzeltme önerileri verebilecekleri bir alanın bırakılmasına özen gösterilmiştir. Bu şekilde hazırlanan çeviri formu Eğitim Yönetimi, Sınıf Öğretmenliği ve Yabancı Diller Eğitimi bölümünde görev yapan 10 akademisyene elektronik posta ya da yüz yüze yapılan görüşmeler yoluyla ulaştırılmıştır. Elde edilen geri bildirimler sonucunda üzerinde uzlaşı sağlanamadığı tespit edilen maddelerde düzeltmeler yapılmıştır. Yapılan düzeltmelerin ardından hazırlanan veri toplama aracının pilot analizleri 220 öğretmen ile gerçekleştirilmiştir.

Asıl uygulama grubunda yer alan 540 sınıf öğretmeninden elde edilen veriler ile Linear Structural Relations (LISREL) 8.80 programı kullanılarak ölçeklerin yapı geçerliğini belirlemek için doğrulayıcı faktör analizine başvurulmuştur. Ölçeklerin özgün formlarındaki faktör yapılarına sadık kalınarak yapılan faktör analizleri sonucunda MTE-EF için elde edilen uyum düzeyleri $\left(\mathrm{x}^{2} / \mathrm{sd}=4.3\right.$, RMSEA=0.07, $\mathrm{CFI}=0.94$, NFI=0.93, $\left.\mathrm{GFI}=0.87\right)$ ile MiDÖ-KF için elde edilen uyum düzeyleri $\left(\mathrm{x}^{2} / \mathrm{sd}=4.6, \mathrm{RMSEA}=0.08, \mathrm{CFI}=0.92, \mathrm{NFI}=0.90, \mathrm{GFI}=0.87\right)$ doğrulamak için kurulan modellerin genel olarak iyi bir uyum düzeyine sahip olduğunu göstermektedir. Ölçeklerin güvenirlik analizleri ise Cronbach alfa iç tutarlılık katsayısı ve madde-toplam korelasyonlarının hesaplanması ile gerçekleştirilmiştir. MTE-EF'nin güvenirlik katsayıları duygusal tükenme boyutunda 0.88 , duyarsızlaşma boyutunda 0.78 , kişisel başarı boyutunda ise 0.74 olarak belirlenmiştir. Güvenirliğe ilişkin bulgular Iwanicki ve Schwab'ın öğretmenlerle gerçekleştirdiği çalışmada elde edilen duygusal tükenme boyutu için 0.90, duyarsızlaşma ve kişisel başarı boyutu için 0.76 (aktaran Maslach, Jackson ve Leiter, 2010) güvenirlik katsayılarıyla tutarlılık göstermektedir. Elde edilen veriler MTE-EF'de yer alan maddelerin madde-toplam korelasyonlarının ise 0.22 ile 0.76 arasında değişkenliğe sahip olduğunu göstermiştir. MiDÖ-KF'nin güvenirlik katsayıları içsel doyum boyutunda 0.82, dışsal doyum boyutunda 0.78 , genel doyum boyutunda ise 0.86 olarak hesaplanmıştır. Elde edilen güvenirlik katsayıları Weiss vd.'nin (1967) ölçeğe ilişkin elde ettikleri içsel doyum boyutunda 0.86, dışsal doyum boyutunda 0.80 ve genel doyum boyutunda 0.90 güvenirlik katsayılarıyla benzerlik taşımaktadır. Ayrıca MíDÖ-KF'nin genel doyum boyutunda belirlenen madde-toplam korelasyonlarına ilişkin değerlerin ise 0.26 ile 0.59 arasında değiştiği görülmüştür.

Sınıf öğretmenlerinin tükenmişlik düzeylerini belirlemek için kullanılan MTE-EF'nin puanlama anahtarına Tablo 2'de yer verilmektedir.

Tablo 2: MTE-EF puanlama anahtarı

\begin{tabular}{lccc}
\hline & & Tükenmişlik & \\
\hline Duygusal Tükenme & Düşük Düzey & Orta Düzey & Yüksek Düzey \\
\hline Duyarsızlaşma & $0-16$ & $17-26$ & 27 ve üzeri \\
\hline Kişisel Başarı & $0-8$ & $9-13$ & 14 ve üzeri \\
\hline
\end{tabular}


MTE-EF'nin puanlama anahtarına göre duygusal tükenme boyutunda alınabilecek en yüksek puan 54, kişisel başarı boyutunda 48, duyarsılaşma boyutunda ise 30'dur (Maslach vd., 2010). Öğretmenlerin kişisel başarı boyutunda aldıkları yüksek puanlar düşük düzeyde tükenmişlik yaşadıklarını göstermektedir. Bir başka ifade ile bu boyutta düşük puan alan öğretmenler yüksek düzeyde tükenmişlik yaşamaktadır.

Sınıf öğretmenlerinin doyum düzeylerini belirlemek için kullanılan MİDÖ-KF'nin puanlama anahtarı ise Tablo 3'te yer almaktadır.

Tablo 3: MíDÖ-KF puanlama anahtarı

\begin{tabular}{lcccc}
\hline & \multicolumn{2}{c}{ Düşük } & Orta & \multicolumn{2}{c}{ Yüksek } \\
\hline \multicolumn{2}{c}{ Doyumsuzluk } & \multicolumn{2}{c}{ Doyum } \\
\hline İçsel Doyum & $12-15$ puan & $16-29$ puan & 30-44 puan & $45-60$ puan \\
\hline Dişsal Doyum & $8-10$ puan & $11-19$ puan & $20-29$ puan & $30-40$ puan \\
\hline Genel Doyum & $20-25$ puan & $26-49$ puan & 50-74 puan & $75-100$ puan \\
\hline
\end{tabular}

Tablo 3 incelendiğinde 5'li Likert tipi bir ölçek olan MiDÖ-KF'nin genel doyum boyutundan alınabilecek en yüksek puan 100, en düşük puan ise 20'dir. Buna göre bir çalışanın iş doyumu ölçeğinden 75 ve üzerinde puan alması yüksek, 26 ile 74 arasında bir puan alması orta, 25 ve altında puanının olması ise düşük düzeyde doyum sağladığını göstermektedir. Weiss vd. (1967) ölçekten 50 ve üzeri puan alan grupların iş doyumu yaşamaya başladıklarının düşünülebileceğini ifade etmektedir.

\subsection{Veri Toplama Araçlarının Uygulanışı}

Mesleki doyum ve tükenmişlik zamana bağlı ortaya çıkan kavramlar olduğu için öğretmenlerin dönem içerisinde bir süre mesleklerini icra etmeleri beklenmiş ve veri toplama aracının uygulama zamanı olarak dönem sonuna denk gelen aylar tercih edilmiştir. Veri toplama aracını uygulamaya başlamadan önce 2 Aralık 2013-23 Ocak 2014 tarihleri arasında hafta içi mesai saatlerini kapsayan bir çalışma takvimi oluşturulmuştur. Araştırmanın yapıldı̆̆ 14 ilçedeki örneklemde yer alan okullara gidilerek toplamda 5500 kilometre mesafe kat edilmiştir. Öncelikle okul müdürleri ile görüşme gerçekleştirilmiş, araştırmanın amaç ve içeriğinden bahsedilerek uygulama için alınan resmi izin yazıları sunulmuştur. Okul müdürlerinden alınan onayın ardından öğretmenlerin ders araları beklenmiştir. Öğretmenlere yapılan gerekli açıklamalardan sonra gönüllülük esasına dayalı olarak veri toplama aracının uygulanmasına geçilmiştir. Araştırmanın veri toplama aşaması çalışma takviminde planlandığı şekilde tamamlanmıştır.

\section{BULGULAR}

Araştırmada elde edilen veriler istatistiksel analizler için Statistical Package for the Social Sciences (SPSS) 15.0 programına aktarılmıştır. Verilerin SPSS'ye işlenmesinden sonra araştırmanın birinci ve ikinci alt probleminin çözümünde aritmetik ortalamalar ve yüzdeler kullanılmıştır. Araştırmanın problem cümlesinin çözümünde ise parametrik bir test olan ilişkisiz örneklemlerde t-testi kullanılmıştır.

\subsection{Bağımsız Sınıfta Görev Yapan Sınıf Öğretmenlerinin Mesleki Doyum ve Tükenmişlik Düzeyleri}

Bağımsız sınıfta görev yapan sınıf öğretmenlerinin mesleki doyum ve tükenmişlik düzeylerini gösteren bulgulara Tablo 4'te yer verilmektedir.

Tablo 4'e göre bağımsız sınıfta görev yapan sınıf öğretmenlerinin içsel doyum boyutundaki puan ortalamaları $(\bar{X}=47.33)$ yüksek düzeyde bulunmaktadır. Dışsal doyum 
boyutunda orta düzeyde $(\overline{\mathrm{X}}=22.45)$ doyum sağlayan öğretmenlerin genel doyum boyutundaki ortalama puanı da $(\overline{\mathrm{X}}=69.78)$ orta düzeydedir. MIDÖ-KF'nin genel doyum boyutunda sinıf öğretmenlerinin \%67.1'i orta düzeyde, \%32.9'u ise yüksek düzeyde iş doyumu yaşamaktadır.

Tablo 4: Bağımsız sınıfta görev yapan sınıf öğretmenlerinin mesleki doyum ve tükenmişlik düzeyleri

\begin{tabular}{lcccc}
\hline Boyutlar & $\bar{X}$ & Düşük Düzey & Orta Düzey & Yüksek Düzey \\
\hline İçsel Doyum & 47.33 & --- & $\% 31.8$ & $\% 68.2$ \\
\hline Dişsal Doyum & 22.45 & $\% 1.3$ & $\% 89.2$ & $\% 9.5$ \\
\hline Genel Doyum & 69.78 & --- & $\% 67.1$ & $\% 32.9$ \\
\hline Duygusal Tükenme & 21.86 & $\% 37.6$ & $\% 26.5$ & $\% 35.9$ \\
\hline Duyarsılaşma & 3.58 & $\% 84.3$ & $\% 10.1$ & $\% 5.6$ \\
\hline Kişisel Başarı & 38.68 & $\% 67.7$ & $\% 16.2$ & $\% 16.1$ \\
\hline
\end{tabular}

Bağımsız sınıfta görev yapan sınıf öğretmenleri duygusal tükenme boyutunda $(\overline{\mathrm{X}}=21.86)$ orta düzeyde, duyarsızlaşma boyutunda ise $(\overline{\mathrm{X}}=3.58)$ düşük düzeyde tükenmişlik yaşamaktadır. Sınıf öğretmenleri tükenmişliğin kişisel başarı boyutunda da $(\bar{X}=38.68)$ düşük düzeyde tükenmişlik yaşamaktadır. Öğretmenlerin \%35.9'u duygusal tükenme boyutunda, \%5.6's1 duyarsızlaşma boyutunda yüksek düzeyde tükenmişlik hissetmektedir. Tükenmişlik ölçeğinin kişisel başarı boyutunda ise öğretmenlerin \%16.1'inin yüksek düzeyde kişisel başarısızlık ve tükenmişlik hislerine sahip oldukları anlaşılmaktadır.

\subsection{Birleştirilmiş Sınıfta Görev Yapan Sınıf Öğretmenlerinin Mesleki Doyum ve Tükenmişlik Düzeyleri}

Birleştirilmiş sınıfta görev yapan sınıf öğretmenlerinin mesleki doyum ve tükenmişlik düzeylerini gösteren bulgular Tablo 5 'te gösterilmektedir.

Tablo 5: Birleştirilmiş sınıfta görev yapan sınıf öğretmenlerinin mesleki doyum ve tükenmişlik düzeyleri

\begin{tabular}{lcccc}
\hline Boyutlar & $\bar{X}$ & Düşük Düzey & Orta Düzey & Yüksek Düzey \\
\hline İçsel Doyum & 45.45 & --- & $\% 38.7$ & $\% 61.3$ \\
\hline Dişsal Doyum & 21.52 & $\% 1.3$ & $\% 94.7$ & $\% 4$ \\
\hline Genel Doyum & 66.97 & --- & $\% 74.7$ & $\% 25.3$ \\
\hline Duygusal Tükenme & 24.17 & $\% 32$ & $\% 24$ & $\% 44$ \\
\hline Duyarsızlaşma & 4.73 & $\% 81.3$ & $\% 8$ & $\% 10.7$ \\
\hline Kişisel Başarı & 36.68 & $\% 58.7$ & $\% 20$ & $\% 21.3$ \\
\hline
\end{tabular}

Tablo 5'e göre birleştirilmiş sınıfta görev yapan sınıf öğretmenleri MiDÖ-KF'nin içsel doyum boyutundan $(\bar{X}=45.45)$ yüksek düzeyde doyum sağlamaktadır. Birleştirilmiş sinıf öğretmenleri yerine getirdikleri mesleğin dişsal doyum $(\bar{X}=21.52)$ ve genel doyum $(\bar{X}=66.97)$ boyutundan ise orta düzeyde doyum elde etmektedir. Araştırmanın bulgularına göre MiDÖKF'nin genel doyum boyutunda sinıf ögretmenlerinin \%74.7'si orta düzeyde, \%25.3'ü ise yüksek düzeyde iş doyumu yaşamaktadır.

Birleştirilmiş sınıf öğretmenleri MTE-EF'nin duygusal tükenme boyutunda ( $\overline{\mathrm{X}}=24.17)$ orta düzeyde, duyarsızlaşma boyutunda ise $(\bar{X}=4.73)$ düşük düzeyde tükenmişlik yaşamaktadır. Öğretmenlerin kişisel başarı boyutundaki tükenmişlikleri ise orta düzeydedir $(\bar{X}=36.68)$. Duygusal tükenme boyutunda öğretmenlerin \%44'ü, duyarsılaş̧ma boyutunda ise \%10.7'si yüksek düzeyde tükenmişlik yaşamaktadır. Tükenmişlik ölçeğinin kişisel başarı boyutunda ise öğretmenlerin \%21.3'ünün yüksek düzeyde kişisel başarısızlık ve tükenmişlik hislerine sahip oldukları anlaşılmaktadır. 


\subsection{Birleştirilmiş ve Bağımsız Sınıfta Görev Yapan Sınıf Öğretmenlerinin Mesleki Doyum ve Tükenmişlik Düzeylerinin Karşılaştırılması}

Sınıf öğretmenlerinin MIDÖ-KF ve MTE-EF'den aldıkları puanların birleştirilmiş ve bağımsız sınıfta çalışma durumuna göre t-testi sonuçları Tablo 6' da gösterilmektedir.

Tablo 6: Mesleki doyum ve tükenmişlik boyutlarının öğretim biçimine göre t-testi sonuçları

\begin{tabular}{lcccccccc}
\hline \multirow{2}{*}{ Boyutlar } & Öğretim Biçimi & $\mathbf{N}$ & $\overline{\mathbf{X}}$ & $\mathbf{S}$ & $\mathbf{s d}$ & $\mathbf{t}$ & $\mathbf{p}$ & $\eta^{\mathbf{2}}$ \\
\hline İçsel Doyum & Bağımsız & 465 & 47.33 & 6.34 & 538 & 2.36 & .018 & .01 \\
& Birleştirilmiş & 75 & 45.45 & 6.49 & & & & \\
\hline Dişsal Doyum & Bağımsız & 465 & 22.45 & 5.62 & 538 & 1.33 & .184 & \\
& Birleştirilmiş & 75 & 21.52 & 5.50 & & & & \\
\hline Genel Doyum & Bağımsız & 465 & 69.78 & 10.42 & 538 & 2.14 & .032 & .01 \\
& Birleştirilmiş & 75 & 66.97 & 10.93 & & & & \\
\hline Duygusal & Bağımsız & 465 & 21.86 & 12.13 & 538 & 1.52 & .127 & \\
Tükenme & Birleştirilmiş & 75 & 24.17 & 12.36 & & & & .070 \\
\hline Duyarsızlaşma & Bağımsız & 465 & 3.58 & 4.97 & 538 & 1.81 & \\
& Birleştirilmiş & 75 & 4.73 & 5.83 & & & & .01 \\
\hline Kişisel Başarı & Bağımsız & 465 & 38.68 & 7.46 & 538 & 2.10 & .036 \\
& Birleştirilmiş & 75 & 36.68 & 8.58 & & & & \\
\hline
\end{tabular}

Tablo 6'ya göre sinıf öğretmenlerinin içsel doyum $(\mathrm{t}(538)=2.36, \mathrm{p}<0.05)$ ve genel doyum $(\mathrm{t}(538)=2.14, \mathrm{p}<0.05)$ düzeylerinde öğretim biçimine göre anlamlı bir farklılık olduğu görülmektedir. Bağımsız sınıfta çalışan öğretmenlerin genel doyumu $(\bar{X}=69.78)$, birleştirilmiş sinıfta görev yapan öğretmenlerin genel doyumundan $(\overline{\mathrm{X}}=66.97)$ daha fazladır. Elde edilen bulgulara göre sınıf öğretmenlerinin içsel ve genel doyumları ile öğretim biçimi arasında anlamlı bir ilişki olduğu söylenebilir. Birleştirilmiş veya bağımsız sınıfta çalışmanın öğretmenlerin içsel ve genel doyum boyutunda küçük bir etki büyüklügüne $\left(\eta^{2}=.01\right)$ sahip olduğu görülürken ölçeğin içsel ve genel doyum boyutlarında gözlenen değişkenliğin \%1'inin öğretim biçimine bağlı olduğu ifade edilebilir.

Tablo 6'da sınıf öğretmenlerinin kişisel başarı boyutundaki tükenmişlik düzeylerinin $(\mathrm{t}(538)=2.10, \mathrm{p}<0.05)$ birleştirilmiş ve bağımsız sınıfta çalışma durumuna göre anlamlı farklılık gösterdiği anlaşılmaktadır. Bağımsız sınıfta görev yapan sınıf öğretmenleri kişisel başarılarını ( $\overline{\mathrm{X}}=38.68)$, birleştirilmiş șnıfta çalışan öğretmenlere göre $(\overline{\mathrm{X}}=36.68)$ daha yüksek puanlamaktadır. Başka bir ifade ile kişisel başarı boyutunda bağımsız sınıfta çalışan öğretmenler birleştirilmiş sınıfta görev yapan öğretmenlere göre daha az tükenmişlik hissetmektedir. Hesaplanan eta-kare değerine $\left(\eta^{2}=.01\right)$ göre öğretim biçiminin kişisel başarı boyutundaki etkisinin küçük olduğu ve bu boyutta gözlenen değişkenliğin \%1'ini açıkladığı söylenebilir. Araştırmanın diğer bulguları tükenmişliğin duygusal tükenme ve duyarsızlaşma boyutları ile doyum ölçeğinin dışsal doyum boyutundan elde edilen sonuçların öğretim biçimine göre anlamlı bir farklılık oluşturmadığını göstermektedir.

\section{TARTIŞMA ve SONUÇ}

Çalışmadan elde edilen bulgular bağımsız sınıfta görev yapan öğretmenlerin iş doyumunun orta düzeyde $(\bar{X}=69.78)$ olduğunu göstermektedir. Ankara'nın merkez ilçelerinde (Güllü, 2009), Elazı ̆ ilinin kırsalında ve kent merkezinde (Yavaş, 2007), Samsun ilinde (Yılmaz ve Ceylan, 2011) ve Antalya il merkezinde (Günbayı ve Toprak, 2010) görev yapan sinıf öğretmenlerinin araştırmanın bulguları ile benzer şekilde orta düzeyde iş doyumuna sahip 
oldukları tespit edilmiştir. Sınıf öğretmenlerinin mesleki doyum düzeyleri alt boyutları bakımından incelendiğinde içsel doyum boyutunda yüksek düzeyde $(\overline{\mathrm{X}}=47.33)$ doyuma sahiptir. Perrachione, Rosser ve Peterson (2008) Amerika'da işini bir meslek olarak içselleştiren ilkokul öğretmenlerinin en çok içsel doyum değişkenlerinden memnuniyet duyduklarını belirtmektedir. Saiti (2007) Yunanistan'da çalışan ilkokul öğretmenlerinin işteki performansları, işlerine karşı duydukları olumlu hisler, işlerine verdikleri değer ve anlam ile öğretmenlerin iş doyumu arasında bir ilişki olduğuna işaret etmektedir.

Bağımsız sınıfta görev yapan öğretmenlerin iş doyumunun dışsal boyutunda orta düzeyde $(\bar{X}=22.45)$ doyum sağladıkları tespit edilmiştir. Malatya ilindeki sınıf ve branş öğretmenlerinin iş doyum düzeylerini belirlemeyi amaçlayan başka bir araştırmada öğretmenler işin niteliğine ilişkin içsel doyum faktörlerinde yüksek düzeyde doyum sağlarken dışsal doyumu etkileyen faktörlerden olan çalışma koşullarında orta ve ücretler boyutunda ise düşük düzeyde iş doyumu sağlamıştır (Günbay1, 2001). Güvenli bir iş ortamı, destekleyici bir yönetim, pozitif okul atmosferi, ilgili aileler ve öğrenciler ile otonomi sahibi öğretmenlerin olduğu çalışma ortamı ile iş doyumu arasında yüksek düzeyde güçlü bir ilişki bulunmaktadır (Perie, Baker ve Whitener, 1997). İngiltere'de çalışan ilkokul öğretmenlerine göre kişisel yeterlilikler ve beceri çeşitliliğini kapsayan işin kendisi iş doyumunun temel nedeni olurken, öğretimi zorlaştıran kurumsal faktörler, çalışanlar arası ilişkiler, çalışma koşulları ve terfi olanakları ise doyumsuzluğa neden olmaktadır (Nias, 1981). Öğretmen maaşlarının gösterilen performansa göre adaletsizlik hissi yaratması ve üst düzey ihtiyaçları karşılamadaki yetersizliği, denetleme ve rehberlik sisteminde yaşanan sorunlar, eğitim politikalarının belirlenmesi ve uygulanmasında karşılaşılan eksiklikler, mesleki gelişime hizmet eden, maddi gelir artışı ve statü sağlayan bir terfi sisteminin bulunmaması, öğrenme-öğretme süreçleri için gereken kaynakları temin etmekte yaşanan sıkıntılar ve katılımlı karar alma süreçlerinden uzak bir çalı̧̧ma ortamı öğretmenlerin iş doyum düzeylerinin azalmasına neden olabilmektedir.

Bağımsız sınıfta görev yapan sınıf öğretmenlerinin MTE-EF'den aldıkları puanlar orta düzeyde duygusal tükenmişlik $(\bar{X}=21.86)$ ve düşük düzeyde duyarsılaşma $(\bar{X}=3.58)$ yaşadıklarını göstermektedir. Sınıf ögretmenlerinin kişisel başarı boyutunda $(\bar{X}=38.68)$ elde ettikleri yüksek puanlar ise bu boyutta düşük düzeyde tükenmişlik yaşandığına işaret etmektedir. Araştırmadan elde edilen bulgulara benzer biçimde Kantas ve Vassilaki (1997) Yunanistan'da çalışan ilkokul öğretmenlerinin; Bryne (1994) Kanada'da çalışan ilkokul öğretmenlerinin; Schwab, Jackson ve Schuler (1986) ise New Hampshire'daki ilköğretim okullarında çalışan öğretmenlerin orta düzeyde duygusal tükenmişlik, düşük düzeyde duyarsızlaşma ve kişisel başarısızlık yaşadıklarını tespit etmişlerdir.

Dorman (2003) iş yükünün oluşturduğu bask1 ile duygusal tükenme arasında güçlü ve pozitif bir ilişki olduğunu vurgulamaktadır. Cano-Garcia, Padilla-Munoz ve Carrasco-Ortiz (2005) ise yöneticilerle ilişkilerin yetersiz olmasının, terfi imkânlarının eksik olmasının, mesleki saygınlığın az olduğunun farkında olmanın, öğrenci sayısının ve bir işte uzun bir süre aynı pozisyonda kalmanın yüksek düzeyde duygusal tükenmenin en iyi yordayıcıları olduğunu ifade etmektedir. Öğretmenlerin duyarsızlaşma boyutundaki düşük düzeydeki tükenmișlikleri öğretmenlik mesleğini vicdani yönü ağır basan bir meslek olarak görmeleri olasıllı̆ı ile açıklanabilir. Öğretmenlerin mesleklerinde karşılaştıkları sorunların ortaya çıkardığı yıpranmayı öğrencilere yansıtmama çabası içinde oldukları ve bu konudaki desteği çalışma ortamındaki meslektaşlarıyla ilişkilerindeki memnuniyetten alabilecekleri söylenebilir.

Birleştirilmiş sınıflı okullarda çalışan sınıf öğretmenlerinden elde edilen veriler genel doyum boyutunda orta düzeyde ( $\overline{\mathrm{X}}=66.97)$ mesleki doyuma sahip olduklarını göstermektedir. Öğretmenler içsel doyum boyutunda yüksek ( $\bar{X}=45.45)$, dişsal doyum boyutunda orta düzeyde ( $\overline{\mathrm{X}}=21.52$ ) bulunsa da ölçekten elde edilen puanlar öğretmenlerin içsel doyum boyutunda orta düzey sinırına $(\bar{X}=45.00)$, dışsal doyum boyutunda ise doyumsuzluk $(\bar{X}=20.00)$ sinırına 
oldukça yakın olduğunu göstermektedir. Öğretmenlerin büyük bir kısmı birleştirilmiş sınıflarda öğrencilerin düzeyleri arasındaki farklılığın oluşturduğu heterojen yapının birden fazla plan yapılmasına, daha fazla zaman ve emek harcanmasına neden olduğunu düşünmektedir (Mason ve Burns, 1995). Birleştirilmiş sınıfta görev yapan öğretmenler konuların öğretimi ve materyallerin hazırlanması için yeterli zamanın olmaması, bir grupla ders işlerken diğer grubun da yönergelere ihtiyaç duyması ve öğrencilerle birebir ilgilenmek için yeterli zamanın olmamasından dolayı sorunlar yaşamaktadır (Veenman, 1995). Kayhan (2008) ise sinıf öğretmenlerinin mesleki doyumu ile öğretim programını tanıma, benimseme ve uygulama arasında düşük düzeyde anlamlı ve pozitif bir ilişki olduğunu ortaya koymuştur. Aynı derslikte birden fazla sınıf düzeyinin sorumluluğunu üstlenen öğretmenler öğrencilerin ihtiyaçlarını tek başlarına karşılamakta güçlük çekmekte ve doyum düzeyleri bu durumdan olumsuz etkilenebilmektedir. Belli bir yetişme tarzı ve eğitimsel bakış açısı ile köy ortamında görev yapan öğretmenlerin kültürel birikimleri ile köyde yaşayan insanların değerleri arasında benzerlikler ya da farklılıklar bulunmaktadır. Yerel halkın eğitimsel gereksinimleri, değer sistemleri ve yaşam tarzları hakkında yeterli bilgiye sahip olmayan öğretmenler kırsal bölgelerdeki okullarda çalışmak konusunda isteksiz olmakta ve kendisini görev yaptığı yere ait hissetmemesi sonucunda okula ve öğrencilere karşı psikolojik olarak yabancılaşmaktadır (UNESCO, 1989). Öğretmenlerin hizmet verdikleri insanlara yabancılaşmasının yanı sıra köyde ve ilçe merkezinde görev yaparken karşılaştıkları önemli sorunlardan birisini halkın öğretmenine güven duymaması olarak gördükleri anlaşılmaktadır (Erdem ve Yaprak, 2011).

Birleştirilmiş sınıfta görev yapan öğretmenlerin dışsal doyum boyutundaki ortalama puanları kendilerini doyumsuzluk sınırına yakın algıladıklarını göstermektedir. Birleştirilmiş sınıf uygulamalarında yeterli bilgi ve birikime sahip olmayan öğretmenler mali ve pedagojik konularda yöneticilerinden yeterince destek bulamadıkları için kendilerini çaresiz, yalnız ve yetersiz hissetmektedir (Aksoy, 2008). Öğretmen yetiştirme programlarında birleştirilmiş sinıflara yeterince yer verilmemesi ve uygun programların geliştirilmemesi, hizmet içi eğitimlerin uygulamaya dönük olmaması, merkezi ve yerel yönetimlerin idari ve ekonomik yönden yeterince destek vermemesi öğretmenlerin dışsal doyum boyutunda doyumsuzluk sınırına yakın olmalarının nedenleri arasında sayılabilir.

Birleştirilmiş sınıfta çalışan öğretmenler MTE-EF'nin duygusal tükenme $(\bar{X}=24.17)$ ve kişisel başarı $(\bar{X}=36.68)$ boyutunda orta düzeyde, duyarsılaşma $(\bar{X}=4.73)$ boyutunda ise düşük düzeyde tükenmişlik yaşamaktadır. Bu öğretmenlerin kişisel başarı boyutundaki puanları düşük düzeyde $(\bar{X}=37.00)$ tükenmişlik sınırına yakındır. Öğretmenlerin görev yaptıkları birleştirilmiş sınıflı okulların idari ve akademik işlerinin tüm sorumluluğunu üzerlerine almaları, taşra ilçelerde görev yapan öğretmenlerin toplu taşıma hizmetleri ya da bireysel olanakları doğrultusunda merkez ilçelerden uzun süren yolculukların ardından okullarına ulaşmaları öğretmenlerin duygusal olarak tükenmişlik hissetmelerinin nedenleri arasında ifade edilebilir.

Sınıf öğretmenlerinin birleştirilmiş ve bağımsız sınıfta çalışma durumuna göre mesleki doyum düzeyleri karşılaştırıldığında içsel $(\mathrm{t}(538)=2.36, \mathrm{p}<0.05)$ ve genel doyum $(\mathrm{t}(538)=2.14$, $\mathrm{p}<0.05$ ) boyutunda bağımsız sınıfta çalışan öğretmenler lehine istatistiksel olarak anlamlı bir fark bulunmaktadır. Birleştirilmiş sınıflarda çalışan öğretmenler aynı anda birden fazla sınıf düzeyini yönetmeye çalışmanın, öğretim programlarını ve materyallerini birleştirilmiş sınıflara uyarlamanın, teknolojik altyapı ve ekonomik kaynakların yetersizliğinin en önemli sorunları ve giderilmesi gereken ihtiyaçları olduğunu belirtmektedir (Dursun, 2006). Can, Can ve Dalaman (2010) araştırmalarında sınıf öğretmenlerinin okullarındaki araç-gereç yeterliliği ile iş doyumları arasında anlamlı ilişkiler olduğunu tespit etmiştir. Birleştirilmiş sınıflarda çalışan öğretmenler bireyselleştirilmiş öğretim, işbirlikli grup çalışmaları ve akran öğrenme gibi öğretmenin rehber olduğu öğretim stratejilerini kullanmak yerine bilgi aktardığı geleneksel toplu öğretim anlayışını benimseyerek farklı sınıf düzeylerine ait öğretim programlarını ayrı ayrı planlaması durumunda 
13

Birleştirilmiş ve Bağımsız Sınıf Öğretmenlerinin Mesleki Doyum ve Tükenmişlik Düzeylerinin Karşılaştırılması

sınıf yönetiminde birçok sorunla karşılaşabilir ve bu sorunları çözmek için kendilerine destek olacak öğretmenlere ulaşması çok kolay olmayabilir.

Sınıf öğretmenlerinin öğretim biçimine göre dışsal doyum boyutunda anlamlı bir farklılık $(\mathrm{t}(538)=1.33, \mathrm{p}>0.05)$ olmamasına rağmen birleștirilmiș sınıfta görev yapan öğretmenler dıșsal doyum boyutunda daha az doyum hissetmektedir. UNESCO (1989) raporu eğitime karşı ilgisiz olan ailelerin ve yetersiz beslenen öğrencilerin olduğu, evde ve okulda yaşayan kültürün uyuşmadığı, materyal ve fiziki altyapı yetersizliklerinin bulunduğu birleştirilmiş sınıflı okullarda çalışan sınıf öğretmenleri bulunduğuna işaret etmektedir. Terfi olanakları, iş yükü ve ödeme dengesi, denetim biçimi ve çalışma koşullarına yönelik eğitim politikalarında yaşanan sorunlar tüm öğretmenleri etkileyen sisteme ilişkin sorunlar olduğundan dolayı birleştirilmiş ve bağımsız sınıfta çalışan öğretmenlerin iş doyumunun dışsal boyutunda anlamlı bir farklılık çıkmamış olabilir.

Duygusal tükenme boyutunda orta düzeyde bulunan birleştirilmiş ve bağımsız sınıfta çalışan sınıf öğretmenlerinin ortalama puanları arasında anlamlı $(\mathrm{t}(538)=1.52, \mathrm{p}>0.05)$ bir fark olmasa da birleştirilmiş sınıflarda çalışan öğretmenlerin duygusal tükenmişlik puanları $(\overline{\mathrm{X}}$ $=24.17)$ bağımsız sınıfta görev yapan öğretmenlere $(\bar{X}=21.86)$ göre bir miktar daha yüksektir. Ertürk ve Keçecioğlu (2012) birleştirilmiş sınıfta çalışan öğretmenlerin materyal eksiklikleri, ulaşım ve ısınma sorunları, sınıfların sosyo-ekonomik düzeyi düşük ailelerin çocuklarından oluşması gibi stres yapıcı durumlarla daha çok karşılaşma potansiyelleri bulunduğunu düşünmektedir. Bilir (2008) ise çevrenin sosyo-ekonomik ve kültürel yapısı, öğrencilerin hazırbulunuşluk düzeyleri, öğretmenlerin yöneticilik ve öğreticilik görevlerinin yanı sıra yerel halkı aydınlatma sorumluluğu nedeniyle birleştirilmiş sınıflarda öğretmenlik yapmanın daha zor olduğunu ifade etmektedir.

Sınıf öğretmenlerinin kişisel başarı boyutundaki tükenmişlik düzeyleri (t(538)=2.10, $\mathrm{p}<0.05)$ bağımsız sınıfta çalışan öğretmenler lehine istatistiksel olarak anlamlı bir farklılık göstermektedir. Öğrencilerin elde ettikleri akademik başarılar öğretmenlerin kişisel başarılarını değerlendirmesinin bir ölçüsü olabilirken, birleştirilmiş sınıflarda öğrenim gören öğrencilerin bağımsız sınıflardaki öğrencilere göre daha başarısız sonuçlar elde ettiği görülmektedir (Saraçoğlu, Böyük ve Tanık, 2012; Palavan, 2012). Bu bulgular birleştirilmiş ve bağımsız sınıfta çalışan öğretmenlerin kişisel başarı puanları arasındaki farklılığın nedenlerinden birisi olabilir.

Araştırmadan elde edilen sonuçlar göstermektedir ki sınıf öğretmenleri birleştirilmiş veya bağımsız sınıfta da görev yapsa iş doyumunun dışsal boyutunda orta düzeyde doyum sağlamaktadır. Öğretmenlik mesleğine ilişkin kariyer ve gelir basamaklarının düzenlenmesi, servis olanakları, öğle yemekleri ve nöbet ücretleri gibi yan gelirlerin oluşturulması, mesleki gelişime düzenli katk1 sunan ve öğretmenlere sayg1 duyan bir denetim biçiminin işlevsel kılınması öğretmenlerin dışsal doyum düzeylerinin artmasını sağlayabilir. Birleştirilmiş sınıfta çalışan öğretmenler, bağımsız sınıfta çalışan öğretmenlere göre birden fazla sınıf düzeyine karşı tek başına sorumlu olmaktan dolayı daha fazla zorluk çektiğini düşünüyor olabilir. Bu nedenle birden fazla sınıf seviyesinin bulunduğu uygulamalarda sınıf içi işleyişi etkin kılacak öğretim uygulamalarının geliştirilmesi, bireyselleştirilmiş öğretim ve seviye grupları ile çalışma gibi birleştirilmiş sınıflarda öğretim için önemli olan ilkelere uygun bir şekilde hizmet içi eğitim programlarının düzenlenmesi öğretmenlerin iş doyum düzeylerini yükseltebilir. Öte yandan nicel bir yaklaşımla tasarlanan bu araştırmada sınıf öğretmenlerinin mesleki doyum ve tükenmişlik düzeylerinin birleştirilmiş ve bağımsız sınıfta çalışma durumuna göre anlamlı farklılık gösterdiği boyutlara ilişkin bulgular ortaya konmuştur. Bu farklılıkların nedenlerinin neler olabileceğine ilişkin derinlemesine ve ayrıntılı bulgular elde edilebilecek nitel araştırmaların desenlenmesinin alana önemli katkılar getireceği düşünülmektedir. 


\section{KAYNAKLAR}

Akıncı, Z. (2002). Turizm sektöründe işgören iş tatminini etkileyen faktörler: Beş yıldızlı konaklama işletmelerinde bir uygulama. Akdeniz I.I. B.F.F Dergisi, 4, 1-25.

Aksoy, N. (2008). Birleştirilmiş sınıflarda eğitim-öğretim: Genç ve deneyimsiz öğretmenlerin görüşlerine dayalı bir araştırma. Eğitim Bilim Toplum Dergisi, 6(21), 83-108.

Ankara İl Milli Eğitim Müdürlüğü (19.06.2012). 2012-2013 yll eğitim istatistikleri. [Çevrim-içi: http://ankara.meb.gov.tr/www/egitim-istatistikleri/icerik/24], Erişim Tarihi: 20.05.2013.

Balc1, A. (1983). İş doyumu ve eğitim yönetimine uygulanması. Ankara Üniversitesi Ĕ̆itim Bilimleri Fakültesi Dergisi, 16(1), 578-586.

Bilir, A. (2008). Birleştirilmiş sınıflı köy ilköğretim okullarında öğretmen ve öğretim gerçeği. Ankara Üniversitesi Eğitim Bilimleri Fakültesi Dergisi, 41(2), 1-22.

Birleşmiş Milletler Ekonomik, Sosyal ve Kültürel Haklar Komitesi (1999). 13 no’lu genel yorum: Eğitim hakkl. [Çevrim-içi: http://insanhaklarimerkezi.bilgi.edu.tr/], Erișim tarihi: 07.03.2014.

Bozkurt, N. (2004, Temmuz). İlköğretim ögretmenlerinde, stres yaratan yaşam olayları ve stresle başa çıkma tarzlarının çeşitli değişkenlerle ilişkisi. XIII. Ulusal Eğitim Bilimleri Kurultayında sunulmuştur, İnönü Üniversitesi Eğitim Fakültesi, Malatya.

Brunswic, É., \& Valérien, J. (2004). Multigrade schools: improving access in rural Africa? UNESCO: International İnstitute for Educational Planning.

Byrne, B. M. (1994). Burnout: Testing for the validity, replication, and invariance of causal structure across elementary, intermediate, and secondary teachers. American Educational Research Journal, 31(3), 645-673.

Can, S., Can, Ş. ve Dalaman, O. (2010). Sinıf öğretmenlerinin çeşitli faktörlere göre iş doyum düzeyleri (Muğla ili örneği). Selçuk Üniversitesi Ahmet Keleşoğlu Eğitim Fakültesi Dergisi, 30, 299-311.

Cano-García, F. J., Padilla-Muñoz, E. M., \& Carrasco-Ortiz, M. Á. (2005). Personality and contextual variables in teacher burnout. Personality and Individual Differences, 38(4), 929-940.

Cordes, C. L., \& Dougherty, T. W. (1993). A review and an integration of research on job burnout. Academy of Management Review, 18(4), 621-656.

Çıngı, H. (1990). Örnekleme kuramı. Ankara: Hacettepe Üniversitesi Fen Fakültesi Basımevi.

Dorman, J. P. (2003). Relationship between school and classroom environment and teacher burnout: A LISREL analysis. Social Psychology of Education, 6(2), 107-127.

Dursun, F. (2006). Birleștirilmiş sınıflarda eğitim sorunları ve çözüm önerileri. Sosyal Bilimler Araştırmaları Dergisi, 2, 33-57.

Erdem, A. R. ve Yaprak, M. (2011). Köy ve ilçe merkezinde görev yapan sınıf öğretmenlerinin halkla etkileșim ve mesleki memnuniyet boyutunda karşılaştı̆̆ sorunlar ve bu sorunların performansına etkisi konusundaki görüșleri. Selçuk Üniversitesi Sosyal Bilimler Enstitüsü Dergisi, 26, 152-162.

Erden, M. (1996). Multigraded classes in Turkey: Improving the quality of instruction. Hacettepe Üniversitesi Eğitim Fakültesi Dergisi, 12, 85-88.

Ertürk, E. ve Keçecioğlu, T. (2012). Çalışanların iş doyumları ile mesleki tükenmişlik düzeyleri arasındaki ilişkiler: Öğretmenler üzerine örnek bir uygulama. Ege Academic Review, 12(1), 41-54.

Freudenberger, H. J. (1974). Staff burn-out. Journal of Social Issues, 30(1), 159-165.

Friesen, D., \& Sarros, J. C. (1989). Sources of burnout among educators. Journal of Organizational Behavior, 10(2), 179-188.

Gömleksiz M. N., Cüro, L. ve Kılınç, H. H. (2011). Birleştirilmiş sınıflarda etkinliklerin uygulanabilirliğine ilişsin öğretmen görüşleri. e-Journal of New World Sciences Academy, 6(2), 1821-1835.

Gözler, A. (2009). Birleştirilmiş sınıflı okulların yönetim problemleri ve çözüm önerileri. Yayımlanmamış doktora tezi, Firat Üniversitesi, Elazı ̆.

Güllü, E. (2009). Sinıf ögretmenlerinin algılarına göre ilköğretim okulu yöneticilerinin liderlik stilleriyle öğretmenlerin iş doyumu düzeyleri arasındaki ilişki. Yayımlanmamış yüksek lisans tezi, Gazi Üniversitesi, Ankara.

Günbay1, İ. (2001). İlköğretim okulu öğretmenlerinin iş doyumu. Kuram ve Uygulamada Eğitim Bilimleri, 1(2), 93112.

Günbayı, İ. ve Toprak, D. (2010). İlköğretim okulu sınıf ve özel sınıf öğretmenlerinin iş doyum düzeylerinin karşılaştırılması. İlköğretim Online, 9(1), 150-169.

Herzberg, F. (1987). One more time: How do you motivate employees? [Çevrim-içi: http://www.sph.ukma.kiev.ua/images/Seminar_4_One_More_Time_How_Do_You_Motivate_Employees\%20(H erzberg).pdf], Erişim tarihi: 20.03.2014.

Kantas, A., \& Vassilaki, E. (1997). Burnout in Greek teachers: Main findings and validity of the Maslach Burnout Inventory. Work \& Stress, 11(1), 94-100.

Karakelle, S. ve Canpolat, S. (2008). Tükenmişlik düzeyi yüksek ilköğretim öğretmenlerinin öğrencilere yaklaşım biçimlerinin incelenmesi. Eğitim ve Bilim, 33(147), 106-120.

Kaya, K. ve Taşdemirci, E. (2005). Birleştirilmiş sınıflar ile bağımsız sınıflarda ilk okuma yazma öğretiminde karşılaşılan sorunların karşıllaştırmalı incelemesi. Erciyes Üniversitesi Sosyal Bilimler Enstitüsü Dergisi, 19(2), 126. 
Kayhan, N. (2008). İlköğretim okulları I. kademede görev yapan sınıf öğretmenlerinin yeni ilköğretim programlarını kabullenmişlik düzeyleri ve mesleki doyumları arasındaki iliş̧kinin incelenmesi. Yayımlanmamış Yüksek Lisans Tezi. Çukurova Üniversitesi.

Kazu, H. ve Aslan, S. (2012). Birleştirilmiş sınıf öğretmenlerinin hayat bilgisi dersi öğretim programına yönelik görüşlerinin incelenmesi (Nitel bir araștırma). Turkish Studies, 7(2), 693-706.

Koçel, T. (2007). İşletme yöneticiliği. İstanbul: Arıkan Basım Yayın Dağıtım.

Köksal, K. (2005). Türkiye'nin gerçeği birleştirilmiş sınıflı okullar. TSA Dergisi, 3, 174-178.

Kudal, Z. A. ve Altun, T. (2012). Birleştirilmiş sınıflarda yapılandırmacı yaklaşımın uygulanabilirliğinin öğretmen görüşleri açısından değerlendirilmesi: Trabzon ili örneği. The Journal of Academic Social Science Studies, 5(8), 89-109.

Leiter, M. P., \& Maslach, C. (2003). Areas of worklife: A structured approach to organizational predictors of job burnout. In P. L. Perrewé and D. C. Ganster (Eds.). Emotional and physiological processes and positive intervention strategies (Research in occupational stress and well-being, Volume 3) (pp. 91-134). Bingley: Emerald Group Publishing Limited.

Little, A. W. (2001). Multigrade teaching: Towards an international research and policy agenda. International Journal of Educational Development, 21(6), 481-497.

Luthans, F. (1992). Organizational behavior. Singapore: McGraw Hill.

Maslach, C. (2003). Job burnout new directions in research and intervention. Current Directions in Psychological Science, 12(5), 189-192.

Maslach, C., \& Jackson, S. E. (1981). The measurement of experienced burnout. Journal of Organizational Behavior, 2(2), 99-113.

Maslach, C., Jackson, S. E., \& Leiter, M. P. (2010). Maslach Burnout Inventory manual. (3rd ed.). mindgarden.com.

Mason, D. A., \& Burns, R. B. (1995). Teachers' views of combination classes. The Journal of Educational Research, 89(1), 36-45.

Milli Eğitim Bakanlığı (MEB) (2012-2013). Milli eğitim istatistikleri örgün ĕgitim 2012-2013. [Çevrim-içi: http://sgb.meb.gov.tr/istatistik/meb_istatistikleri_orgun_egitim_2012_2013.pdf], Erişim tarihi: 15.06.2013.

Milli Eğitim Bakanlığına Bağlı Okul ve Kurumların Yönetici ve Öğretmenlerinin Norm Kadrolarına İlişkin Yönetmelik (1999). [Çevrim-içi: http://mevzuat.meb.gov.tr/html/8301.html], Erişim tarihi: 20.09.2013.

Minibaş, J. (1990). Özel ve devlet ilkokullarında görev yapan ögretmenlerin iş tatmini düzeyi ve bu düzeyin frustrasyon karşısında gösterilen tepki tipi ve agresyon yönü ile ilişkisi. Yayınlanmamış Yüksek Lisans Tezi. Marmara Üniversitesi.

Nias, J. (1981). Teacher satisfaction and dissatisfaction: Herzberg's 'two-factor' hypothesis revisited. British Journal of Sociology of Education, 2(3), 235-246.

Palavan, Ö. (2012). Birleştirilmiş ve bağımsız sınıflı ilköğretim 4. sınıf öğrencilerinin sosyal bilgilerin kazanımlarına erişim düzeyleri. Ondokuz Mayıs Üniversitesi Ĕ̈itim Fakültesi Dergisi, 31(2), 281-294.

Perie, M., Baker, D. P., \& Whitener, S. (1997). Job satisfaction among America's teachers: Effects of workplace conditions, background characteristics and teacher compensation. Washington: National Center for Education Statistics.

Perrachione, B. A., Rosser, V. J., \& Petersen, G. J. (2008). Why Do They Stay? Elementary Teachers' Perceptions of Job Satisfaction and Retention. Professional Educator, 32(2).

Russell, D. W., Altmaier, E., \& Van Velzen, D. (1987). Job-related stress, social support, and burnout among classroom teachers. Journal of Applied Psychology, 72(2), 269-274.

Saiti, A. (2007). Main factors of job satisfaction among primary school educators: Factor analysis of the Greek reality. Management in Education, 21(2), 28-32.

Sağ R., Savaş, B. ve Sezer, R. (2008). Burdur'daki birleştirilmiş sınıf öğretmenlerinin özellikleri, sorunları ve ihtiyaçları. İn̈nü Üniversitesi Eğitim Fakültesi Dergisi, 10(1), 37-56.

Saraçoğlu, S., Böyük, U. ve Tanık, N. (2012). Birleştirilmiş ve bağımsız sınıflarda öğrenim gören ilköğretim öğrencilerinin bilimsel süreç beceri düzeyleri. Türk Fen Eğitimi Dergisi, 9(1), 83-100.

Sarı, H. (2004). An analysis of burnout and job satisfaction among Turkish special school headteachers and teachers, and the factors effecting their burnout and job satisfaction. Educational Studies, 30(3), 291-306.

Schwab, R. L., Jackson, S. E., \& Schuler, R. S. (1986). Educator burnout: Sources and consequences. Educational Research Quarterly, 10(3), 14-30.

Şahin, A. E. (2003). Birleştirilmiş sınıflar uygulamasına ilişkin öğretmen görüşleri. Hacettepe Üniversitesi Eğitim Fakültesi Dergisi, 25, 166-175.

Tengilimoğlu, D. (2005). Hizmet işletmelerinde liderlik davranışları ile iş doyumu arasındaki ilişkinin belirlenmesine yönelik bir araştırma. Ticaret ve Turizm Eğitim Fakültesi Dergisi, 1, 23-45.

United Nations Educational, Scientific and Cultural Organization (UNESCO) (1989). Multigrade teaching in single teacher primary schools. [Çevrim-içi: http://unesdoc.unesco.org/images/0008/000845/084515eo.pdf], Erişim tarihi: 22.09.2013.

Veenman, S. (1995). Cognitive and noncognitive effects of multigrade and multi-age classes: A best-evidence synthesis. Review of Educational Research, 65(4), 319-381. 
Weiss, D. J., Dawis R. V., England, G. W., \& Lofquist, L. H. (1967). Manual for the Minnesota Satisfaction Questionnaire, [Çevrim-içi: https://www.psych.umn.edu/psylabs/vpr/pdf_files/Monograph\%20XXII\%20\%20Manual\%20for\%20the\%20MN\%20Satisfaction\%20Questionnaire.pdf], Erişim tarihi: 12.01.2013.

Yavaş, T. (2007). Kırsal alanda ve kent merkezinde çalı̧̧an sınıf öğretmenlerinin iş doyum düzeylerinin karşılaştırılması. Yayınlanmamış yüksek lisans tezi, Fırat Üniversitesi, Elazı̆̆.

Yılmaz, A. ve Ceylan, Ç. B. (2011). İlköğretim okul yöneticilerinin liderlik davranış düzeyleri ile öğretmenlerin iş doyumu ilişkisi. Kuram ve Uygulamada Eğitim Yönetimi Dergisi, 17(2), 277-394.

\section{Extended Abstract}

Combining more than one class level in one classroom and carrying on the teaching and learning process with one teacher makes up the framework of combination classrooms in primary level. The difficulties faced in combination classrooms include insufficient undergraduate teacher education, lack of teaching materials in combination classrooms, and low economic status of families (Erden, 1996). Teachers who work in single-grade classrooms face with problems such as crowded classrooms, disciplinary difficulties, violence, low salaries, indifferent parents, and negative management attitudes, which are sources of stress for them (Russell, Altmaier \& Van Velzen, 1987). In this sense, the research questions of our study were "What are the levels of job satisfaction and job burnout of teachers who work in single-grade classrooms and combination classrooms?" and "Are there significant differences between single-grade classroom teachers and combination classroom teachers in terms of job satisfaction and job burnout?".

Based on the Ministry of National Education Ankara City Directorate, between 2012 and 2013 there were 15544 classroom teachers working in Ankara. To decrease the environmental factors effecting the sense of job satisfaction and job burnout, we choose single-grade classroom teachers from the same locations where we choose combination classroom teachers in our sample. We determined that there were 5 districts and 9 provinces that met this criteria and 8057 teachers worked in these regions. We used stratified sampling method to determine our sample and we treated each region as one strata. We took each state school as a sampling unit and used clustered sampling for schools. Schools were selected by simple random sampling in this sampling method. We took the ratios of teachers in each region in the sampling population into consideration during sampling. 324 classroom teachers from the central districts of Çankaya, Sincan, Altındağ, Etimesgut and Gölbaşı and 141 teachers from the provinces of Beypazarı, Ayaş, Polatlı, Akyurt, Çubuk, Haymana, Kalecik, Bala and Şereflikoçhisar were included in the study sample. For the teachers who worked in combination classrooms, we did not do sampling and included 75 of the 86 teachers who worked in the 14 regions, which was a representation of $87 \%$.

We used Maslach Burnout Inventory-Educators Survey (MBI-ES) as a data collection tool to determine the perceived burnout levels of classroom teachers. To determine perceived job satisfaction levels of teachers we used Minnesota Satisfaction Questionnaire-Short Form (MSQ-SF). To determine the construct validity of these instruments, we used Linear Structural Relations (LISREL) 8.80 software and conducted confirmatory factor analysis. We kept the factor structures in the original forms and conducted the factor analysis and obtained the following conformity levels for MBI-ES (x2/sd=4.3, RMSEA=0.07, $\mathrm{CFI}=0.94, \mathrm{NFI}=0.93, \mathrm{GFI}=0.87$ ) and for MSQ-SF (x2/sd=4.6, RMSEA=0.08, CFI=0.92, NFI=0.90, GFI=0.87) which show that the models we formed for confirmatory purposes have good conformity levels. We determined that the MBI-ES had reliability coefficient of 0.88 for the emotional exhaustion dimension, 0.78 for the depersonalization, and 0.74 for the personal accomplishment dimension. The data obtained shows that item-total correlations of the items in MBI-ES range from 0.22 to 0.76 . MSQ-SF had reliability coefficient of 0.82 for the intrinsic satisfaction dimension, 0.78 for the extrinsic satisfaction dimension and 0.86 for the general satisfaction dimension. The item-total correlations of the MSQ-SF for the general satisfaction dimension ranged from 0.26 to 0.59 .

The findings of the study showed that single-grade classroom teachers had high intrinsic satisfaction. They had medium level extrinsic and general satisfaction scores. $67.1 \%$ of the teachers had medium, 32.9\% of them had high levels of general satisfaction based on MSQ-SF. Classroom teachers had medium levels of emotional exhaustion and low levels of depersonalization. They also had low levels of personal accomplishment. $35.9 \%$ of the teachers had high levels of emotional exhaustion while $5.6 \%$ had high levels of depersonalization. We observed that $16.1 \%$ of the teachers had high scores for lack of personal accomplishment and burnout. Teacher who worked in combination classrooms had high levels of intrinsic satisfaction scores in MSQ-SF. They had medium levels of extrinsic and general satisfaction. 
17

Findings of the study showed that $74.7 \%$ of the combination classroom teachers had medium level while $25.3 \%$ had high levels of general job satisfaction. Teachers had medium levels of emotional exhaustion and personal accomplishment while low levels of depersonalization. $44 \%$ of the teachers had high levels of emotional exhaustion and $10.7 \%$ of the teachers had high levels of depersonalization. We found that $21.3 \%$ of the teachers had high scores for lack of personal accomplishment.

There is a significant difference between combination classroom teachers and single-grade classroom teachers in terms of intrinsic and general satisfaction. The single-grade classroom teachers have higher levels of intrinsic and general satisfaction. Working in a combination classroom or a single-grade classroom has a small effect size on intrinsic and general satisfaction. $1 \%$ of the observed change in intrinsic and general satisfaction levels can be attributed to the type of teaching. There was also significant difference between combination classroom teachers and single-grade classroom teachers in terms of personal accomplishment. Teachers working in the single-grade classrooms had higher scores of personal accomplishment than combination classroom teachers. The type of teaching had a small influence on the perception of personal accomplishment which only explained $1 \%$ of the observed change.

\section{Ek-1}

BÖLÜM-2

Yönerge: Ag̣ağıda verilen maddelerin karģısındaki seçeneklerden size en uygun gelen seçeneği " $\mathrm{X}$ " işareti ile işaretleyiniz

\begin{tabular}{|c|c|c|c|c|c|c|c|}
\hline $\mathrm{P}^{2}$ & 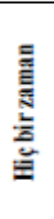 & 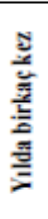 & 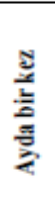 & 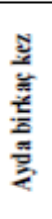 & 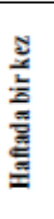 & 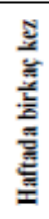 & 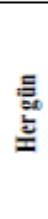 \\
\hline 1. Ögretmenlikten duygusal olaral & $\square$ & $\square$ & $\square$ & $\square$ & $\square$ & $\square$ & $\square$ \\
\hline 2. Okulda günü bitirdiğimde kendimi bitkin hissediyorum. & $\square$ & $\square$ & $\square$ & $\square$ & $\square$ & $\square$ & $\square$ \\
\hline $\begin{array}{l}\text { 3. Saba } \\
\text { hissediy }\end{array}$ & $\square$ & $\square$ & $\square$ & $\square$ & $\square$ & $\square$ & $\square$ \\
\hline 4. Öğrencilerimin bir konu hakkında ne hissettiğini kolayca anlayabiliyorum. & $\square$ & $\square$ & $\square$ & $\square$ & $\square$ & $\square$ & $\square$ \\
\hline 5. Baz & $\square$ & $\square$ & $\square$ & $\square$ & $\square$ & $\square$ & $\square$ \\
\hline 6. Bütün gün oğrencilerle çalıģmak beni ș & $\square$ & $\square$ & $\square$ & $\square$ & $\square$ & $\square$ & $\square$ \\
\hline 7. Ögrencilerimin sorus & $\square$ & $\square$ & $\square$ & $\square$ & $\square$ & $\square$ & $\square$ \\
\hline 8. Ögretmenliǧ̣in beni tükettiğini hissediyorum. & $\square$ & $\square$ & $\square$ & $\square$ & $\square$ & $\square$ & $\square$ \\
\hline $\begin{array}{l}\text { 9. Bir } \\
\text { hissedi }\end{array}$ & $\square$ & $\square$ & $\square$ & $\square$ & $\square$ & $\square$ & $\square$ \\
\hline 10. Ōğretmenliğe başladığımdan beri oğrencilere karşı daha çok duyars & $\square$ & $\square$ & $\square$ & $\square$ & $\square$ & $\square$ & $\square$ \\
\hline 11. Ōğretmenliğin beni duygusal olara & $\square$ & $\square$ & $\square$ & $\square$ & $\square$ & $\square$ & $\square$ \\
\hline 12. Kendimi çok zinde hissediyorum. & $\square$ & $\square$ & $\square$ & $\square$ & $\square$ & $\square$ & $\square$ \\
\hline 13. Ōğrretmenlik mesleğinin beni hayal kurlklığına uğrattığını düş̧ün & $\square$ & $\square$ & $\square$ & $\square$ & $\square$ & $\square$ & $\square$ \\
\hline 14. Ōğretmenlikte is yükümün çok fazla olduğunu hissediyorum. & $\square$ & $\square$ & $\square$ & $\square$ & $\square$ & $\square$ & $\square$ \\
\hline 15. Bazı oğrencilere ne olduğunu gerçekten umursamyyorum. & $\square$ & $\square$ & $\square$ & $\square$ & $\square$ & $\square$ & $\square$ \\
\hline 16. Ō̈̆rencilerle çahỵıyor olmak & $\square$ & $\square$ & $\square$ & $\square$ & $\square$ & $\square$ & $\square$ \\
\hline nunı ögrencilerimle birlikte kolayca yaratabili & $\square$ & $\square$ & $\square$ & $\square$ & $\square$ & $\square$ & $\square$ \\
\hline e gerçekleştirdiǧim bir & $\square$ & $\square$ & $\square$ & $\square$ & $\square$ & $\square$ & $\square$ \\
\hline 19. Ōğretmenlikte kayda değer pek çok şey başardm. & $\square$ & $\square$ & $\square$ & $\square$ & $\square$ & $\square$ & $\square$ \\
\hline 20. Ōğretmenliğe daha fazla dayanamayacakmığım gibi hissediyorum. & $\square$ & $\square$ & $\square$ & $\square$ & $\square$ & $\square$ & $\square$ \\
\hline $\begin{array}{l}\text { 21. İ̧̧imde karģlaşthğım duygusal problemlerle oldulkça sakin bir şekild } \\
\text { ediyorum. }\end{array}$ & $\square$ & $\square$ & $\square$ & $\square$ & $\square$ & $\square$ & $\square$ \\
\hline 22. Ō. ğrencilerin bazı sorunlanndan dolayı beni suçladıklarmu hi & $\square$ & 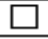 & $\square$ & $\square$ & $\square$ & $\square$ & L \\
\hline
\end{tabular}

* Lütfen her bir maddeyi cevapladığınızdan emin olunuz ve anketi cevaplamaya üçūncủ bölüm ile devam ediniz 
Ek-2

\section{BÖLÜM-3}

Yönerge: Bu ölçek öğretmenlik hakkında hissettiklerinizi belirlemeyi amaçlamaktadır. Aşağıda ögretmenlik mesleğinin çeşitli yönleriyle ilgili maddelere yer verilmektedir. Her bir maddeyi dikkatlice okuyunuz. Maddelere ilişkin hissettiklerinizi en iyi ifade eden seçeneğı " $\mathrm{X}$ " işareti ile işaretleyiniz. Lütfen her bir maddeye cevap veriniz.

\begin{tabular}{|c|c|c|c|c|c|}
\hline $\mathrm{N}^{\mathrm{N}} \mathrm{N}$ & 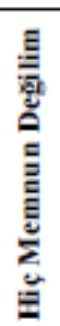 & 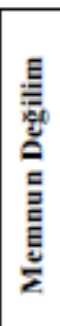 & 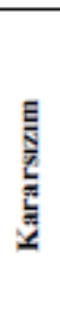 & $\begin{array}{l}\mathrm{E} \\
\mathrm{E} \\
\mathrm{E} \\
\mathrm{E} \\
\mathrm{E}\end{array}$ & 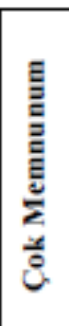 \\
\hline 1. Ōğretmenliğin beni sürekli mesgul etmesinden... & $\square$ & $\square$ & $\square$ & $\square$ & $\square$ \\
\hline 2. Smıfimda tek başıma çalıģabilme olanağından... & $\square$ & $\square$ & $\square$ & $\square$ & $\square$ \\
\hline 3. Zaman zaman farklı seyleri yapabilme olanağından... & $\square$ & $\square$ & $\square$ & $\square$ & $\square$ \\
\hline 4. Toplum içinde saygun "biri" olma şansından... & $\square$ & $\square$ & $\square$ & $\square$ & $\square$ \\
\hline 5. Yöneticilerimin ögretmenleri yönetme tarzından... & $\square$ & $\square$ & $\square$ & $\square$ & $\square$ \\
\hline 6. Eğitim denetmenlerinin karar verme yeterliğinden... & $\square$ & $\square$ & $\square$ & $\square$ & $\square$ \\
\hline 7. Değerlerime aykın olmayan şeyleri yapabiliyor olmaktan... & $\square$ & $\square$ & $\square$ & $\square$ & $\square$ \\
\hline 8. Ögretmenliğin sağladığı daimi kadro güvencesinden... & $\square$ & $\square$ & $\square$ & $\square$ & $\square$ \\
\hline 9. Diğer insanlar için bir şeyler yapabilme olanağından... & $\square$ & $\square$ & $\square$ & $\square$ & $\square$ \\
\hline 10. İnsanlara ne yapmaları gereltiğini sōyleme gücümden... & $\square$ & $\square$ & $\square$ & $\square$ & $\square$ \\
\hline 11. Sahip olduğum becerileri kullanabileceğim işleri yapma olanağından... & $\square$ & $\square$ & $\square$ & $\square$ & $\square$ \\
\hline 12. Eğgitim politikalarını uygulamaya konma şeklinden... & $\square$ & $\square$ & $\square$ & $\square$ & $\square$ \\
\hline 13. Aldığım ücret ve is yükümden... & $\square$ & $\square$ & $\square$ & $\square$ & $\square$ \\
\hline 14. Öğretmenlikte sahip olduğum terfi olanağından... & $\square$ & $\square$ & $\square$ & $\square$ & $\square$ \\
\hline 15. Kararlanım uygulama özgürliǧünden... & $\square$ & $\square$ & $\square$ & $\square$ & $\square$ \\
\hline 16. Öğretmenlik yaparken kendi yöntemlerimi kullanma olanağından... & $\square$ & $\square$ & $\square$ & $\square$ & $\square$ \\
\hline 17. Çalışma koşullanmman... & $\square$ & $\square$ & $\square$ & $\square$ & $\square$ \\
\hline 18. Okulumdaki ögretmenlerin birbirleriyle geçinme şeklinden... & $\square$ & $\square$ & $\square$ & $\square$ & $\square$ \\
\hline 19. İ̧̧imi iyi yaptığımdan dolayı aldığım övgüden... & $\square$ & $\square$ & $\square$ & $\square$ & $\square$ \\
\hline 20. Öğretmenlikten aldığmm başan hissinden... & $\square$ & $\square$ & $\square$ & $\square$ & $\square$ \\
\hline
\end{tabular}

